\title{
The first records of a rare species of Reticularia olivacea (Myxomycetes) and Hypsizygus marmoreus (Fungi) in Inner Asia
}

\author{
Anastasia Vlasenko ${ }^{1 *}$,Dondov Budsuren ${ }^{2}$, Chechekmaa Nazyn ${ }^{3}$ \\ ${ }^{1}$ Central Siberian Botanical Garden SB RAS, 630090 Novosibirsk, Russia \\ ${ }^{2}$ Plant Protection Research Institute of Mongolia, 17024 Khan-Uul district, Ulaanbaatar, Mongolia \\ ${ }^{3}$ Department of General Biology and Ecology, Tuva State University, 667000 Kyzyl, Russia
}

\begin{abstract}
A rare species of fungi, Hypsizygus marmoreus, collected in the Republic of Tyva, Russia, and a rare species of myxomycetes, Reticularia olivacea, collected in the Mongolia, were recorded for the first time in Inner Asia. The article provides a photographs of fruiting bodies of these species, distribution in world is provided.
\end{abstract}

\section{Introduction}

The species Enteridium olivaceum Ehrenb. was described in 1818. Later, he was transferred to the genus Reticularia in 1829 as Reticularia olivacea (Ehrenb.) Fr. Reticularia olivacea belongs to the Tubiferaceae family from Liceales.

Some authors highlight the order Reticulariales Leontyev, Schnittler, S.L. Stephenson, Novozhilov et Shchepin and propose to re-erect the generic name Licaethalium, already proposed in the monograph of Rostafiński (1875), R. simulans and R. olivacea transferred to the genus Licaethalium [1].

Reticularia olivacea common in (North America (Canada, USA, Mexico), South America (Argentina, Chile), Europe (Belgium, Great Britain, Denmark, Sweden, Netherlands, Norway, Finland, France, Spain, Lithuania, Germany, Ukraine), Asia (Japan, Russia Far East), Australia.) [2].

Reticularia olivacea was first collected by us in Inner Asia.

The species Agaricus marmoreus Peck was first described in 1872, later, he was transferred H.E. Bigelow to the genus Hypsizygus in 1976. The fungus belongs to the family Lyophyllaceae was a member of Agaricales.

Hypsizygus marmoreus is a commercially cultivated edible and medicinal species [3]. Hypsizygus marmoreus was first collected by us in Inner Asia.

Hypsizygus marmoreus found in North America (Canada, USA, Mexico), Europe (Austria, Estonia, Sweden, Ukraine) and in Asia (China, Chinese Taipei, Japan). The location of the fungus belongs to regions with a temperate and subtropical climate, the only location in the tropics is known from Mexico [4].

\footnotetext{
* Corresponding author: Anastasiamix81@mail.ru
} 
In the world, according to GBIF and literary sources, less than 150 records are known, the species is not included in the IUCN Red List of threatened species. In Russia, H. marmoreus is a rare species.

In the Asian part of Russia, H. marmoreus was recorded in Primorsky Krai, Krasnoyarsk Krai. For the European part of Russia, the species was recorded by S.V. Volobuev for the Oryol Oblast [5]. Our record of H. marmoreus in the Republic of Tuva is the fourth in Russia and the first in Inner Asia.

\section{Materials and methods}

The samples of $R$. olivacea was obtained by the "moist chamber" method on the bark of live Picea obovata Ledeb. from Mongolia. The "moist chamber" method is traditional in the study of myxomycetes of the epiphytic substrate complex [6-10].

Fruiting bodies of $H$. marmoreus were collected during expedition in the Republic of Tuva.

Species identification was carried out using a Carl Zeiss EVO MA 10 scanning electron microscope, a Stemi DV4 stereo microscope, Axiolab Ere and Zeiss Axio Imager A1 light microscopes (Carl Zeiss Microscopy, Germany) in CSBG SB RAS. Specimens were prepared for scanning electron microscopy using traditional SEM techniques, summarized as follows. For microscopy, sporocarps of myxomycetes were preserved as permanent slides in polyvinyl lactophenol. The nomenclature follows IndexFungorum [11].

\section{Results and Discussion}

The substrates for the experiments with "moist chambers" for R. olivacea (Fig. 1 a) were collected 01.10.2019 in cedar-spruce forest (Fig. 1 b) in the Bogd Khan Uul Biosphere Reserve near Ulaanbaatar, $47.7629^{\circ} \mathrm{N}, 107.0006^{\circ} \mathrm{E}, 1769 \mathrm{~m}$. The experiments with "moist chambers" were started on November 6, 2019. R. olivacea grown in "moist chambers" March 12, 2020.

Fruiting bodies of H. marmoreus (Fig. 1 c, d) were collected by us August 15, 2020 in Republic of Tuva in the State Natural Customer Khutinsky, near Sevi, $52.7174^{\circ} \mathrm{N}$, $94.789683^{\circ} \mathrm{E}, 1138 \mathrm{~m}$, in larch forest with an admixture of birch, on the trunk of a live birch.

\section{Conclusions}

Reticularia olivacea morphologically similar to $R$. simulans (Rostaf.) D.W. Mitch. and which was previously considered as a variation of Reticularia olivacea var. simulans (Rostaf.) Nann.-Bremek. Currently, $R$. simulans recognized as an independent species [1112]. Different understanding of the taxonomic position of this species by different authors does not allow assessing the geographical distribution of this taxon, since it can be stored in herbaria and published under the names as Reticularia olivacea, $R$. simulans, $R$. olivacea var. simulans.

The diversity of individual groups of spore organisms in the Republic of Tuva is well studied [13], whereas fungi are still an understudied group in this region. We plan to continue studying the diversity of fungi and myxomycetes in the Republic of Tuva and Mongolia. 

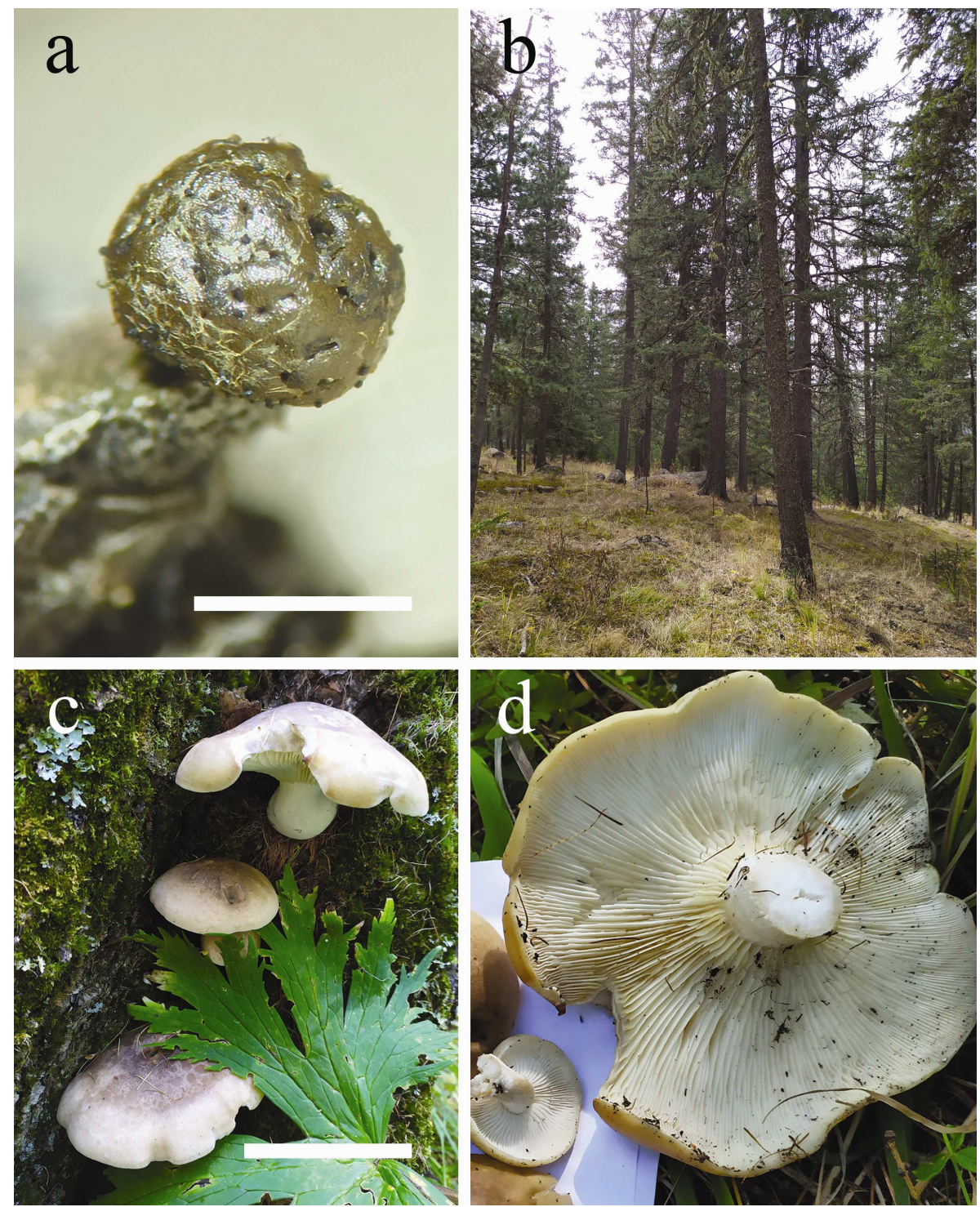

Fig. 1. A - Sporocarp of Reticularia olivacea. B - habitat of R. olivacea in the Mongolia. C, D Fruiting bodies of Hypsizygus marmoreus. Bars : A $-2 \mathrm{~mm}, \mathrm{C}-10 \mathrm{~cm}$.

Acknowledgements. The work was funded by RFBR and MCESSM according to the research project 19-54-44002 Mong_T.

\section{References}

1. D. V. Leontyev, M. Schnittler, S. L. Stephenson, Y. K. Novozhilov, O. N. Shchepin. Phytotaxa, 399, 3 (2019)

2. GBIF Secretariat. GBIF Backbone Taxonomy. Checklist dataset. https://www.gbif.org/species/5436313 (2021)

3. F. Wu, J. Tang, F. Pei, S. Wang, G. Chen, Q. Hu, L. Zhao. Eur. Food Res. Technol., 240 (2015) 
4. GBIF Secretariat. GBIF Backbone Taxonomy. Checklist dataset. https://www.gbif.org/species/2530653 (2021)

5. S. Yu. Bolshakov, L. B. Kalinina, S. V. Volobuev, Yu. A. Rebriev, A. G. Shiryaev, Yu. R. Khimich, V. A. Vlasenko, A. V. Leostrin, N. V. Shakhova, A. V. Vlasenko, T. Dejidmaa, O. N. Ezhov, I.V. Zmitrovich. Mikol. I fitopatol., 54, 6 (2020)

6. H. C. Gilbert, G. W. Martin, Univ. Iowa Stud. Nat. Hist., 15, 3 (1933)

7. M. Harkoenen, T. Ukkola. Stapfia, 73 (2000)

8. A. V. Vlasenko, N. V. Filippova, V. A. Vlasenko. Phytotaxa, 367, 1 (2018)

9. A. V. Vlasenko, N. V. Filippova, V. A. Vlasenko. Phytotaxa, 416, 1 (2019)

10. A.V. Vlasenko. Samara J. Sc., 9, 4 (2020)

11. IndexFungorum. http://www.indexfungorum.org/Names/Names.asp (2021)

12. D. W. Mitchell. Systematic. Geograph. Plants, 74, 2 (2004)

13. Ch. N. Sambyla. Sibirsk. Ecol. J., 14, 2 (2007) 